\title{
First-line treatment of advanced ALK-positive non-small-cell lung cancer
}

\author{
This article was published in the following Dove Press journal: \\ Lung Cancer: Targets and Therapy \\ 18 September 2015 \\ Number of times this article has been viewed
}

\author{
Shipra Gandhi' \\ Hongbin Chen ${ }^{2}$ \\ Yujie Zhao ${ }^{2}$ \\ Grace K Dy ${ }^{2}$ \\ 'Department of Internal Medicine, \\ State University of New York, \\ ${ }^{2}$ Department of Medicine, Roswell \\ Park Cancer Institute, Buffalo, NY, \\ USA
}

Correspondence: Grace K Dy Department of Medicine, Roswell Park Cancer Institute, Elm \& Carlton Streets, Buffalo, NY 14263, USA

Tel +I 7168452300 ext 3094

Fax +I 7I68458935

Email grace.dy@roswellpark.org

\begin{abstract}
Non-small-cell lung cancer (NSCLC) is one of the leading causes of cancer deaths, both within the US and worldwide. There have been major treatment advances in NSCLC over the past decade with the discovery of molecular drivers of NSCLC, which has ushered in an era of personalized medicine. There are several actionable genetic aberrations in NSCLC, such as epidermal growth factor receptor and anaplastic lymphoma kinase (ALK). In 3\%-7\% of NSCLC, a chromosomal inversion event in chromosome 2 leads to fusion of a portion of the ALK gene with the echinoderm microtubule-associated protein-like 4 (EML4) gene. The constitutive activation of the ALK fusion oncogene renders it vulnerable to therapeutic intervention. This review focuses on the first-line treatment of advanced ALK-positive NSCLC using ALK inhibitors. Crizotinib was the first agent proven to be efficacious as first-line treatment for ALKpositive NSCLC. However, acquired resistance inevitably develops. The central nervous system is a sanctuary site that represents a common site for disease progression as well. Hence, more potent, selective next-generation ALK inhibitors that are able to cross the blood-brain barrier have been developed for treatment against crizotinib-resistant ALK-positive NSCLC and are also currently being evaluated for first-line therapy as well. In this review, we provide summary of the clinical experience with these drugs in the treatment of ALK-positive NSCLC.
\end{abstract}

Keywords: non-small-cell lung cancer, ALK, first line, crizotinib, pemetrexed

\section{Introduction}

Non-small-cell lung cancer (NSCLC) is one of the leading causes of cancer deaths, both within the US and worldwide. The estimated number of new cases of lung cancer in 2015 is approximately 220,000 in the US alone, with deaths from the disease estimated at $158,000 .^{1,2}$ Majority of patients with NSCLC are generally diagnosed in advanced stage with limited overall survival (OS) benefit from cytotoxic chemotherapy as the only systemic treatment modality option until the turn of the 21 st century. Before the turn of this century, the treatment of stage IV NSCLC with a platinum-based doublet backbone remained relatively unchanged for decades. ${ }^{3}$ Chemotherapy provides modest improvements in survival for advanced NSCLC, but the 5-year survival rate is dismal at $<5 \%$.

Recent advances in the understanding of the complex biology of NSCLC and identification of specific genetic and molecular subgroups enabled the development of specific inhibitors to target oncogenic driver mutations. This underlies the basic approach toward precision medicine in which NSCLC is at the forefront, with the goal to improve survival outcomes of patients using therapies predicted to be most efficacious based on the genetic characteristics of the underlying disease and the individual patient. ${ }^{4}$ 
There are multiple oncogenic aberrations described to date in NSCLC. ${ }^{5}$ In 2007, ALK was identified as an oncogenic target in NSCLC ${ }^{6}$ serendipitously at the time of clinical development of a multikinase inhibitor whose spectrum of activity included ALK. This resulted in an unprecedented swift timeline toward accelerated US Food and Drug Administration (US FDA) approval in 2011 of the first targeted therapy against $\mathrm{ALK}{ }^{6}$

\section{ALK-positive NSCLC \\ The EML4-ALK fusion protein}

In a small subset of NSCLC tumors, a chromosomal inversion event leads to fusion of a portion of the ALK gene with the echinoderm microtubule-associated protein-like 4 (EML4) gene. This inversion in chromosome 2 juxtaposes the $5^{\prime}$ end of the EML4 gene with the $3^{\prime}$ end of the ALK gene, resulting in the novel fusion oncogene EML4-ALK (Figure 1 shows the formation of the EML4-ALK fusion oncogene). The resulting chimeric protein, EML4-ALK, contains an N-terminus with coiled-coiled domain that mediates oligomerization derived from EML4 and a C-terminus containing the entire intracellular tyrosine kinase domain of ALK. The resulting EML4-ALK fusion protein is thus constitutively activated and transforming, and this fusion oncogene rearrangement defines a distinct clinicopathologic subset of NSCLC. ${ }^{6}$

Currently, immunohistochemistry (IHC) plays a role as a screening modality for ALK rearrangement to select patients who may benefit from ALK-directed therapy. It is a rapid and relatively inexpensive method for diagnosing ALK-rearranged NSCLC. However, commercially available ALK antibodies lack the sensitivity to specifically detect the EML4-ALK fusion protein. ${ }^{7}$ The sensitivity and specificity of IHC ALK

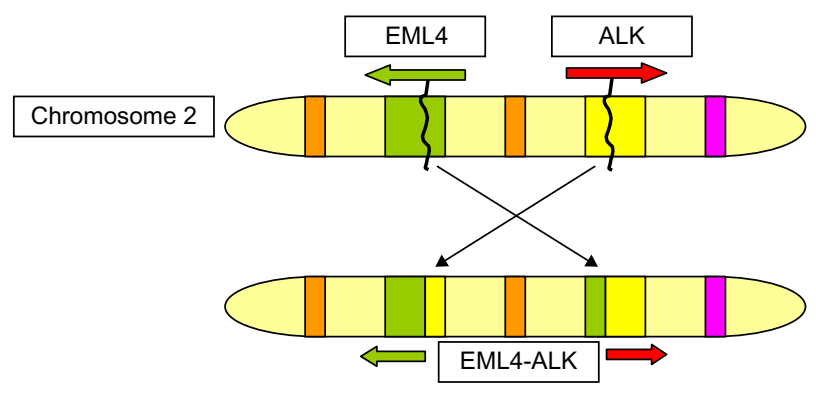

Figure I A chromosomal inversion in chromosome 2 juxtaposes the $5^{\prime}$ end of the EML4 gene with the $3^{\prime}$ end of the ALK gene resulting in the fusion oncogene EML4-ALK.

Notes: The resulting chimeric protein, EML4-ALK, contains an $\mathrm{N}$-terminus derived from the EML4 and a C-terminus containing the intracellular tyrosine kinase domain of ALK.

Abbreviations: EML4, echinoderm microtubule-associated protein-like 4; ALK, anaplastic lymphoma kinase. testing ranges from $67 \%$ to $100 \%$ and from $93 \%$ to $100 \%$, respectively, using fluorescent in situ hybridization (FISH) as the standard procedure. ${ }^{89}$ Several authors have recommended a two-tiered approach, whereby patients initially be screened with IHC and those with faint, moderate, or intense staining be tested by FISH for confirmation of ALK positivity. ${ }^{10}$ Another modality developed to capture ALK fusion transcripts, and which has been confirmed to be a reliable technique for the diagnosis of EML4-ALK is multiplex reverse transcription-polymerase chain reaction (RT-PCR). An advantage with RT-PCR is that it is free from subjectivity in analysis, unlike IHC and FISH. ${ }^{11}$ Considering the higher sensitivity associated with RT-PCR for detecting ALKrearrangements in NSCLC, some studies have recommended to include it for ALK inhibitor treatment in the prospective clinical trials. ${ }^{12-14}$ However, it is limited by requirement for fresh frozen tissue samples for optimal testing conditions, and its validation and reproducibility in conventional formalinfixed paraffin-embedded tissue sections can be challenging. FISH has been approved as a companion diagnostic tool by the US FDA. It is currently considered as a gold standard to test for the presence of ALK rearrangement. However, FISH is time consuming and there exist multiple variants of EML4-ALK rearrangements like RNA editing abnormalities associated with intron abnormalities, which FISH is not able to detect. ${ }^{15-17}$ Patients with ALK rearrangements have been observed to show excellent response to ALK-targeted therapies, such as crizotinib, ceritinib, and alectinib; hence, it is important to not miss any cases and develop a sensitive and standardized approach. Next-generation sequencing (NGS) is an upcoming diagnostic technique for allowing comprehensive sequencing of entire genomes, exomes, and transcriptomes. NGS is able to detect EML4 and ALK genes that are separated by small rearrangements that prevent detection by FISH assay. ${ }^{17} \mathrm{~A}$ study by Ali et al ${ }^{18}$ showed that NGS may be more sensitive in detecting ALK rearrangements than FISH in lung cancer. Hence, in light of this data, there is a need to reconsider if FISH by itself is sufficient as standard modality for detecting ALK rearrangements and basing treatment decisions on its results. ${ }^{18}$

Since the discovery of the first EML4-ALK fusion oncogene in 2007, nearly 30 specific variants of EML4-ALK have been reported to date, with exon 20 of ALK typically as the first exon fused to different exons of EML4 due to variable break points that result in different truncations of the EML4 partner. Rare ALK fusion variants with other gene partners have also been described in lung-cancer specimens, namely, TRK, TFG, KIF5B, HIP1, KLC1, and STRN. ${ }^{19}$ Majority of these fusion variants also contain exon 
20 of ALK as the first exon fused to the corresponding gene partner. ${ }^{19}$

\section{Clinicopathologic and radiologic characteristics of patients with EML4- ALK fusion oncogene}

EML4-ALK fusion and other ALK rearrangements occur in $3 \%-7 \%$ of patients with NSCLC (henceforth referred to as "ALK-positive" lung cancer). ${ }^{20-22}$ On the basis of the global estimate of 1.8 million new lung-cancer cases in 2012, ${ }^{23}$ it can be anticipated that there are at least 60,000 patients with newly diagnosed "ALK-positive" NSCLC worldwide. Tumors that contain the EML4-ALK fusion oncogene or its variants are associated with specific clinical features, including never or light-smoking history, younger age, and adenocarcinoma with signet ring or acinar histology. Generally, the ALK gene arrangements are mutually exclusive of epidermal growth factor receptor (EGFR) or KRAS mutations. ${ }^{24}$ Radiologic features that appear to be associated with ALK+ status include central tumor location, lack of pleural tail sign, and large pleural effusion. ${ }^{25}$

ALK-positive NSCLC appears to be particularly sensitive to pemetrexed chemotherapy. In a retrospective study of 89 eligible patient cases conducted to explore whether the progression-free survival (PFS) with pemetrexed differs between ALK-positive and other major molecular subtypes, Camidge et $\mathrm{al}^{26}$ described that with pemetrexed used as first-line treatment in 48\%, median PFS (mPFS) was 5.5 months (95\% confidence interval [CI]: 1-9) in EGFRmutant, 7 months (1.5-10) in KRAS-mutant, 9 months (3-12) in ALK-positive, and 4 months (3-5) in EGFR-/ KRAS-/ALK-WT (wild type). In a multivariate analysis adjusting for all the variables, the only variable associated with prolonged PFS on pemetrexed was ALK positivity (hazard ratio [HR] 0.36 [95\% CI: 0.17-0.73], $P=0.0051$ ). Thus, the mPFS among 19 ALK-positive patients who received different pemetrexed-containing regimens as first-, second-, or fourth-line therapy was 9 months, exceeding that of 37 ALK/EGFR/KRAS-negative patients by 5 months. Similarly, in a study by Lee et $\mathrm{al}^{27}$ of patients with advanced NSCLC between 2007 and 2010 who were screened for EGFR mutations and ALK rearrangements, the efficacy of pemetrexed in 15 patients with ALK-positive were compared to 80 patients with ALK-negative (EGFR-mutant or -WT for both ALK and EGFR) NSCLC. The overall response rate (ORR) was superior in ALK-positive patients compared with EGFR-mutant or -WT patients ( $46.7 \%$ versus $4.7 \%$ versus $16.2 \%, P=0.001$ ). The TTP (time to progression) among ALK-positive patients was longer than EGFR-mutant or -WT patients (9.2 versus 1.4 versus 2.9 months, $P=0.001$ ). ALK positivity alone was observed to be a significant predictor for ORR (HR $=0.07,95 \%$ CI: $0.01-0.32 ; P=0.001$ ) and TTP (HR $=0.44,95 \%$ CI: $0.24-0.80 ; P=0.007$ ). ALK positivity was independently significant regardless of treatment line (HR $=0.43$, 95\% CI: $0.24-0.77 ; P=0.005$ ). Hence, the TTP among 15 ALK-positive patients who had received singleagent pemetrexed in the second-line setting and beyond was 9.2 months; in contrast, the median TTP of 37 ALK-negative, EGFR-WT controls was only 2.9 months. The study suggested that ALK positivity was independently predictive of pemetrexed efficacy in NSCLC patients. ${ }^{27}$

Another multicenter retrospective analysis ${ }^{28}$ of PFS compared 121 ALK-positive patients versus 266 patients with advanced, ALK-negative, EGFR-WT NSCLC (79 with KRAS mutations and 187 with WT KRAS) treated with pemetrexed-based chemotherapy. This study is the largest retrospective analysis to date of ALK-positive and ALK-negative patients treated with pemetrexed-based chemotherapy. The PFS of all pemetrexed-based regimens was similar among ALK-negative and ALK-positive patients, except in the specific setting of first-line platinum/pemetrexed where there was statistically significant difference in mPFS of 8.5, 4.1, and 5.4 months in ALK-positive/KRAS and EGFR WT, ALK and EGFR-WT/KRAS-mutant, and ALK-/EGFR-/KRAS-WT patients, respectively. No difference in PFS was observed between ALK-positive and ALK-negative patients among patients with a never or light-smoking history $(0-10$ pack-year smoking history) treated with first-line platinum/pemetrexed. Among the never/light-smoking patients, the PFS on firstline platinum/pemetrexed may be prolonged regardless of ALK status. The analysis demonstrated that ALK-positive patients do not have a longer PFS on pemetrexed-based chemotherapy compared with ALK-negative controls, except in the setting of first-line platinum/pemetrexed combinations. It was concluded that the PFS on all pemetrexed regimens including first-line platinum/pemetrexed is similar between ALK-positive and ALK-negative patients within the subset of never or light-smoking patients. This finding reaffirms the previously known observations that smoking status influences treatment outcomes to therapy beyond that determined by the genotype. ${ }^{28}$ Nonetheless, the efficacy and toxicity profile favored the use of the platinum/pemetrexed combination as a comparator arm for the initial registrational study evaluating first-line therapy in this patient population.

\section{Approved ALK inhibitors}

The constitutive activation of the ALK fusion oncogene renders it vulnerable to therapeutic intervention. Figure 2 
shows the constitutive activation of ALK tyrosine kinase due to aberrant expression of ALK, leading to downstream signaling pathways that lead to cell proliferation and survival. In the seminal paper described by Soda et al, ${ }^{29}$ inhibition of ALK induced cell death in cells expressing this fusion protein.

Treatment of EML4-ALK transgenic mice in vivo with ALK inhibitors results in tumor regression, supporting the notion that ALK-driven lung cancers are highly dependent on the fusion oncogene. ${ }^{28}$

Two tyrosine kinase inhibitors, crizotinib and ceritinib, have established roles in the treatment of ALK-positive NSCLC, and additional agents are under development.

\section{Crizotinib}

Crizotinib (also known as PF-02341066) is a multitargeted small-molecule ALK inhibitor, which had been originally developed as an inhibitor of the mesenchymal epithelial transition (c-MET) growth factor receptor tyrosine kinase. In addition to c-MET in cell-based assays, crizotinib also demonstrates nanomolar inhibition of ROS1, RON as well as ALK. ${ }^{30}$ As alluded to earlier, its accelerated approval for ALK-positive NSCLC was based on impressive Phase I clinical data initially published in 2010 by Kwak et $\mathrm{al}^{31}$ and later updated by Camidge et $\mathrm{al}^{32}$ in 2012 .

\section{Trials: crizotinib in ALK-positive NSCLC}

\section{Phase I trials}

The Phase I study PROFILE 1001 initially included 37 patients with various advanced stage tumors, including colorectal cancer (six patients), sarcoma (four patients), and NSCLC (three patients), refractory to standard treatments, aimed to assess the maximum tolerated dose of crizotinib. Given the important activity of crizotinib in two patients with NSCLC with ALK rearrangement, this Phase I study was extended in this particular molecular genotype. The extension of this Phase I trial was published in October 2010 in the New England Journal of Medicine. After screening 1,500 patients with NSCLC in search of ALK rearrangement by FISH, the investigators identified and included 82 patients with advanced ALKpositive NSCLC. All enrolled patients received oral crizotinib at a dose of $250 \mathrm{mg}$ twice daily in 28-day cycles, with tumor response measured every 2 months using Response Evaluation Criteria in Solid Tumors. At 6.4 months of treatment (median duration of treatment), $57 \%$ of patients had objective response of either partial (PR) or complete response (CR) (PR in 46 patients and CR in one patient) and $33 \%$ had stable disease. The Phase I study was further expanded to evaluate 143 patients. Approximately 60.8\% (95\% CI: 52.3-68.9) had an objective response ( 87 of 143 patients), including three CRs and 84 PRs. The median duration of response was 49.1 weeks $(95 \% \mathrm{CI}$ : 39.3-75.4). This response is largely independent of sex, age, condition, and the number of previous treatments. The mPFS was 9.7 months (95\% CI: 7.7-12.8) and the median duration of response was 49 weeks. ${ }^{31,32}$

\section{Phase II trials}

A noncomparative Phase II multicenter single-arm trial (PROFILE 1005) 33,34 investigated the efficacy and safety of crizotinib administered to patients with ALK-positive

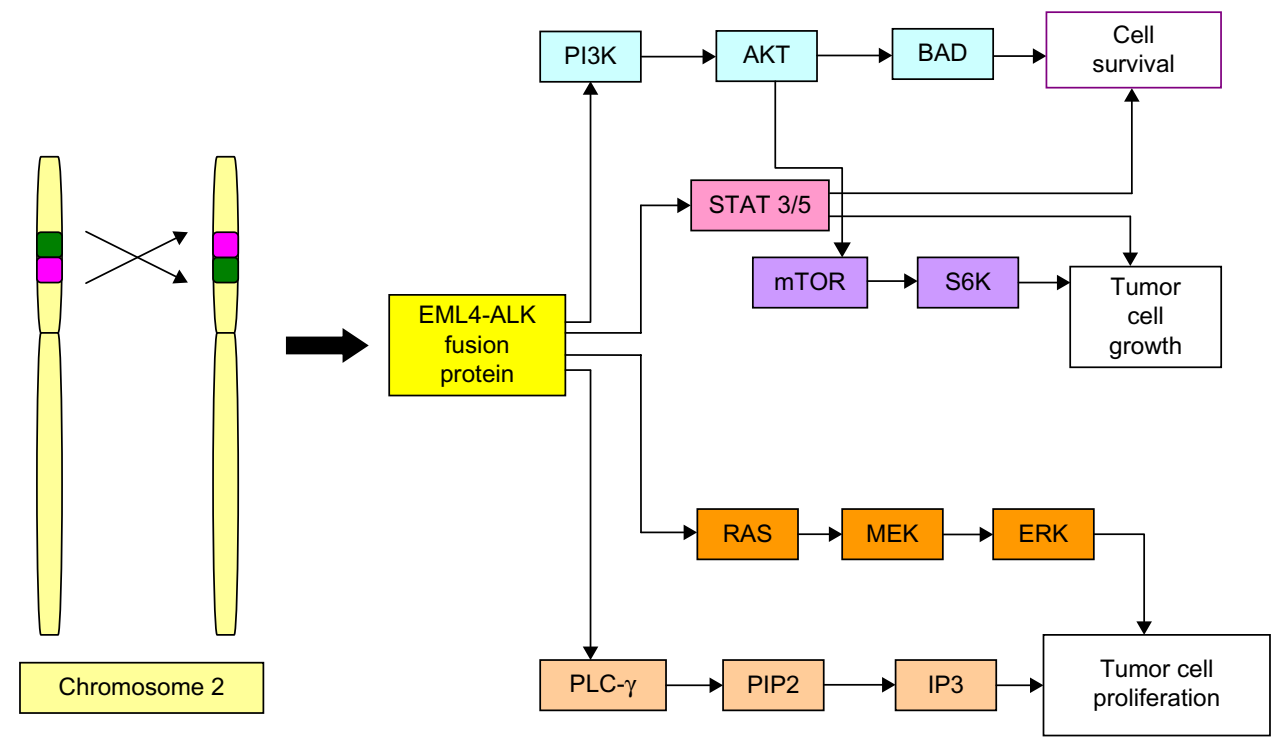

Figure 2 EML4-ALK fusions are due to small inversions within chromosome 2p.

Notes: These fusions lead to aberrant expression of ALK and constitutive activation of the ALK tyrosine kinase and further downstream signaling pathways. Hence, this results in uncontrolled proliferation and survival of cancer cells.

Abbreviations: EML4, echinoderm microtubule-associated protein-like 4; ALK, anaplastic lymphoma kinase. 
advanced NSCLC progressing after chemotherapy. The majority were women (53\%), nonsmokers (65\%), diagnosed with adenocarcinoma (92\%), having an Eastern Cooperative Oncology Group (ECOG) scale of performance status of 0-2 ( $83 \%)$, and received $\geq 2$ lines of chemotherapy ( $85 \%)$. As of the data lock on January 1, 2012, 901 ALK-positive NSCLC patients were enrolled, and all received crizotinib therapy. ${ }^{34}$ Efficacy data reported on the mature population of 261 patients enrolled and treated by February 2011 showed that the observed ORR was $59.8 \%(n=155)$ for 259 patients who were evaluable for response, with an mPFS of 8.1 months.

Hence, the results of this Phase II study confirmed the results in PROFILE 1001, showing that crizotinib demonstrated a benefit in response rate and PFS with good tolerance in this group of previously treated ALK-positive patient population. On the basis of the response rates in the Phase I and II studies, the US FDA granted accelerated approval to crizotinib to treat patients with advanced NSCLC harboring ALK rearrangements in $2011 .{ }^{35}$ The study was later extended to Phase III trials to assess the benefit of crizotinib in patients with advanced stage NSCLC with ALK rearrangement.

A Phase II randomized chemoradiation study (NCT01822496) is currently ongoing to evaluate the role of crizotinib in the treatment of locally advanced stage III ALKpositive NSCLC. ${ }^{36}$ This Phase II randomized study compares standard chemoradiation to 60 Gy versus 12 weeks of induction therapy with crizotinib in EML4-ALK-translocated adenocarcinoma. Patients who did not achieve either PR or CR after 6 weeks will immediately receive conventional concurrent chemoradiation therapy. Otherwise, chemoradiation will be started 2 weeks after completion of induction therapy. The primary endpoint is PFS. The study will accrue an estimated 234 patients.

\section{Phase III trials}

A randomized Phase III trial was designed to compare crizotinib to standard second-line therapy. PROFILE 1007 is a randomized Phase III trial consisting of 347 patients with locally advanced or metastatic ALK-positive NSCLC previously treated with platinum-based chemotherapy. The patients were randomized into two arms to receive crizotinib or standard second-line chemotherapy: pemetrexed or docetaxel. The study was conducted at 105 sites in 21 countries. The primary endpoint was PFS and the secondary endpoint was OS. Crizotinib demonstrated superiority over docetaxel and pemetrexed; the mPFS was 7.7 months in the crizotinib arm versus 3 months in the chemotherapy arm $(P<0.0001)$. Comparing each drug separately, the mPFS was 7.7 months in the crizotinib arm versus 4.2 months in the pemetrexed arm $(P=0.0004)$; versus 2.6 months in the docetaxel arm $(P<0.0001)$. No difference was observed in OS between the two groups (20.3 months with crizotinib versus 22.8 months with chemotherapy; HR, 1.02; $P=0.54)$, likely owing to crossover of patients from chemotherapy to crizotinib. The response rate to crizotinib was almost triple compared with that of chemotherapy: $65.3 \%$ in crizotinib arm versus $19.3 \%$ in the chemotherapy $\operatorname{arm}(P<0.0001)$. Comparing crizotinib with each drug separately, the response rate to crizotinib was $65.7 \%$ versus $29.3 \%$ in the pemetrexed arm; versus $6.9 \%$ in the docetaxel arm. The safety profile was acceptable and the quality of life was higher for patients treated with crizotinib $(P<0.0001)$. This Phase III randomized trial solidified the role of crizotinib, then to become the standard second-line treatment after platinum-based chemotherapy, in patients with ALK-positive NSCLC. ${ }^{37}$

Given the impressive clinical activity outlined earlier in the salvage therapy settings, establishing the role of crizotinib as first-line therapy in advanced ALK-positive NSCLC was imperative. A multicenter, randomized open-label Phase III trial (PROFILE 1014) was conducted by Solomon et $\mathrm{al}^{38}$ comparing crizotinib with chemotherapy in 343 patients with advanced treatment naive ALK-positive nonsquamous NSCLC. Patients were randomly assigned to receive oral crizotinib at a dose of $250 \mathrm{mg}$ twice daily or chemotherapy (pemetrexed plus cisplatin/carboplatin): 172 to crizotinib and 171 to chemotherapy. Crossover to crizotinib after disease progression was permitted for patients receiving chemotherapy. The primary endpoint was PFS. PFS was significantly longer with crizotinib than with chemotherapy (mPFS, 10.9 months versus 7.0 months) (95\% CI: 6.8-8.2) (HR for progression or death with crizotinib, 0.45 ; $95 \% \mathrm{CI}$ : $0.35-0.60, P<0.001)$. Objective response rates were $74 \%$ and $45 \%$, respectively $(P<0.0001)$. Crizotinib was superior to standard first-line pemetrexed plus cisplatin chemotherapy in patients with previously untreated advanced ALK-positive NSCLC.$^{38}$ The HR favored crizotinib across most subgroups, defined according to the stratification factors. Crizotinib treatment was also associated with a significantly higher response rate and greater improvements in patient-reported measures of renal functioning, key lung-cancer symptoms (cough/dyspnea/chest pain and fatigue), and global quality of life. ${ }^{38}$ This study demonstrated superior outcome with crizotinib over pemetrexed plus platinum (carboplatin/cisplatin) chemotherapy as first-line therapy in patients with previously untreated advanced ALK-positive NSCLC and has defined the role of ALK inhibitors in the first-line setting. Its role in the adjuvant setting is currently being evaluated in the Phase III ALCHEMIST treatment trial, randomizing 
an estimated 378 patients with resected stage IB-IIIA ALK-positive NSCLC to either crizotinib or placebo (NCT02201992).

\section{Ceritinib}

Ceritinib (also known as LDK378) is a second-generation ALK inhibitor that is approximately 20 times more potent than crizotinib. It is currently approved for patients unable to tolerate crizotinib or with crizotinib-resistant ALK-positive NSCLC. Preclinical studies suggested that ceritinib had significant activity against cells that were either sensitive or resistant to crizotinib, including resistant tumors with the most common L1196M and G1269A resistance mutations. After the maximum tolerated dose was established in the Phase I (ASCEND-1) study, ceritinib was studied in a dose expansion cohort of NSCLC patients with ALK rearrangement. ${ }^{39-41}$ Results from that expansion cohort were updated at the 2014 American Society of Clinical Oncology meeting. ${ }^{41}$ A total of 246 patients with ALK-positive NSCLC were treated with ceritinib at a dose of $750 \mathrm{mg}$ once daily, which necessitated at least one dose reduction in nearly $60 \%$ of the patients due to adverse events. The objective response rate was $58 \%$ overall, $55 \%$ in 163 patients who had prior crizotinib treatment, and $66 \%$ in 83 ALK inhibitor-naïve patients. The median duration of response ( 9.7 months) in the entire cohort had not yet been reached in ALK inhibitor-naïve patients and was reached in 7.4 months in those with prior crizotinib treatment. The mPFS for the entire cohort was 8.2 months, including 6.9 months for those previously treated with an ALK inhibitor and not yet reached (lower bound of $95 \% \mathrm{CI}$ is 8.3 months) for those who had not previously received an ALK inhibitor. On the basis of these findings, ceritinib was approved by the US FDA in April 2014 for patients who have progressed on or are intolerant of crizotinib. Indeed, sequential crizotinib and ceritinib use achieves a combined mPFS of 17 months with OS of 49 months when patients receive sequential therapy. ${ }^{42}$ Given these encouraging results, two Phase III trials are currently ongoing. ASCEND-4 study will be randomizing an estimated 348 patients with newly diagnosed advanced ALK-positive NSCLC who had not been previously treated with any systemic anticancer therapy (including other ALK inhibitors) to either ceritinib or platinum (either cisplatin or carboplatin) and pemetrexed combination (NCT01828099). The ASCEND-5 study will be evaluating ceritinib versus either pemetrexed or docetaxel in approximately 236 ALKpositive NSCLC patients who had received one or two prior treatment regimens (NCT01828112). ${ }^{43}$

\section{Alectinib}

Alectinib (also known as CH542802/RO542802) is a highly potent-selective ALK inhibitor, with activity against L1196M gatekeeper mutation as well as other secondary mutations such as G1269A. ${ }^{44,45}$ Results from the first-inhuman Phase I/II study with alectinib in a Japanese population of crizotinibnaïve patients with ALK-positive advanced NSCLC were first reported by Seto et al. ${ }^{46}$ Seventy patients ( 24 in the Phase I study and 46 in the Phase II study) were enrolled. In the Phase II portion of the study, 43 of 46 (93.5\%) patients achieved an objective response (93.5\%) including two CRs (4.3\%) and 41 PRs (89.1\%). The mean duration of treatment was 14.8 months, and at 1 year of follow-up, the median PFS had not been reached. Another Phase I/II study was conducted in either crizotinib-pretreated or -intolerant ALK-positive advanced NSCLCs patients. ${ }^{47}$ Overall, 44 of 47 patients were assessable for activity in the Phase I study, with an ORR of 55\% (24/44 patients). As the recommended Phase II dose of $300 \mathrm{mg}$ twice daily required eight capsules per dose (20 and $40 \mathrm{mg}$ preparation), a pharmacology study was conducted (JPJ28927) to evaluate bioequivalence with the $150 \mathrm{mg}$ capsule preparation. The pharmacokinetic parameters were similar, and no food effect was seen with the $150 \mathrm{mg}$ capsules. ${ }^{48}$ Efficacy results were as expected, with objective response rate confirmed in $60 \%$. US FDA had granted breakthrough-therapy designation to alectinib for ALK-positive advanced NSCLCs, which have progressed to crizotinib in June 2013, with approval being expected soon. Japan was the first country to approve the use of alectinib in ALK-positive NSCLC in July 2014. ALEX study is a headto-head randomized Phase III (NCT02075840) trial that was started in August 2014 to compare alectinib versus crizotinib as first-line treatment in ALK-positive NSCLC. Approximately 286 patients will be enrolled to this ongoing trial.

\section{Special population: treatment of intracranial metastases in ALK- positive NSCLC}

The treatment of ALK-positive NSCLC is often complex due to the frequent occurrence of brain metastases: initial occurrence of brain metastasis has been reported in 15\%$35 \%$ of cases,,$^{37,49,50}$ and, over the course of first-line therapy with either crizotinib or chemotherapy, the frequency of brain metastases can increase to $60 \%$. Brain metastases are associated with many complications: some of these are neurocognitive, psychological, physical impairments, ${ }^{37}$ severe comorbidity, and a decreased life expectancy. ${ }^{51,52}$ 
Pemetrexed has been used in combination with other chemotherapy for the treatment of intracranial metastases in NSCLC. Although clinical activity has been reported, ${ }^{53}$ the distribution of pemetrexed to the central nervous system (CNS) is limited and might result in low efficacy for CNS metastases. ${ }^{54}$

While crizotinib has anecdotal activity against brain metastasis, it is generally viewed to have limited role against CNS metastases given its poor penetration against the blood-brain barrier as manifested in low cerebrospinal fluid concentration. ${ }^{55,56}$ Indeed, the CNS is a frequent site of disease progression, manifesting as either parenchymal or leptomeningeal metastases. ${ }^{57}$ Nonetheless, continued crizotinib administration after radiotherapy for isolated CNS progression was a feasible approach utilized prior to the availability of second-generation ALK inhibitors. ${ }^{58}$

The Phase I ASCEND-1 study was instrumental in demonstrating the efficacy of ceritinib for intracranial metastases in ALK+ NSCLC. In a subset analysis, 124 out of total population of 246 had brain metastases at study entry. ${ }^{41}$ Among these 124 patients, 98 had been treated by an ALK inhibitor before, and 26 were ALK inhibitor treatment-naïve. ALK inhibitor-naïve patients with CNS metastases treated with ceritinib experienced an ORR of $69 \%$ and an mPFS of 8.3 months. In comparison, in patients previously treated with another ALK inhibitor, the ORR was $50 \%$ and the mPFS was 6.7 months. The intracranial response rate for patients with measurable brain metastases at baseline was $40.0 \%$ in patients who had received previous ALK inhibitor therapy, while this was $75 \%$ in ALK inhibitor-naïve patients.

Alectinib is also another CNS-penetrant ALK inhibitor and its activity against brain metastases in crizotinib-resistant ALK-positive patients was elucidated early in the doseescalation portion of the Phase I/II AF-002JG study ${ }^{47}$ Out of 47 patients enrolled in the Phase I portion, 21 patients had CNS metastases at baseline. Approximately $52 \%$ of these patients had an objective response. Of four patients who had not had brain radiotherapy, two had a best CNS response of $\mathrm{CR}$, one had PR, and one had stable disease. Of nine patients with measurable baseline CNS lesions, five had PR, two had stable disease, and two had progression disease, one of whom had pseudoprogression due to radiation necrosis. This clinical phenomenon needs to be recognized as it is difficult to distinguish from true disease progression and correct classification is required to avoid discontinuation of ALK inhibitor therapy, particularly if there is no extracranial disease progression.

\section{Acquired resistance to ALK inhibitors}

Approximately $30 \%$ of ALK-positive advanced NSCLC patients show intrinsic resistance to crizotinib. Moreover, despite initial response to treatment, all patients who initially respond to treatment eventually develop resistance after an average of 1 year since treatment start. ${ }^{38}$ Acquired resistance is defined as evidence of clinical progression after initial clinical benefit. Several distinct mechanisms of resistance have been reported in the literature. In approximately one-third of resistant cases, tumors have acquired a secondary mutation within the ALK tyrosine kinase domain. The most common resistance mutation to crizotinib is the gatekeeper L1196M mutation, followed by the G1269A mutation. The ALK ${ }^{1151 \text { Tins }}$ and G1202R mutations are notable since they confer high-level resistance to crizotinib as well as to next-generation ALK inhibitors such as ceritinib. ${ }^{59}$ Other mutations described in ceritinib-resistant tissues include $\mathrm{F} 1174 \mathrm{C} / \mathrm{V}^{60}{ }^{60}$ A novel gatekeeper mutation V1180L and another mutation I1171T/N/S were identified that conferred resistance to both alectinib and crizotinib but remained sensitive to ceritinib and other next-generation ALK inhibitors. ${ }^{61,62}$

A second mechanism of crizotinib resistance is amplification of the ALK fusion gene. This can occur alone or in combination with a secondary resistance mutation. ${ }^{63}$ Finally, a number of alternative or bypass signaling pathways mediate resistance to crizotinib. Bypass tracks described so far in patients with ALK-positive NSCLC with acquired resistance to crizotinib include the development of EGFR or KRAS mutations or activation of WT EGFR, HER2-, or KIT-receptors. ${ }^{64-66}$ Conversely, activated MET signaling has been shown to potentially mediate resistance to alectinib but not to crizotinib ${ }^{67}$ with the latter demonstrating clinical efficacy anecdotally. ${ }^{68}$ Using patient-derived specimens, Crystal et $\mathrm{al}^{69}$ performed a pharmacological screen to determine effective drug combinations in the setting of acquired resistance. The combination of ALK and MEK or Src inhibitors were identified. This knowledge underlies the rationale to develop next-generation compounds and/or to combine therapies to overcome resistance. Moreover, in the context of recognized intratumor heterogeneity and dynamic expression of immune checkpoint modulators in ALK-positive NSCLC, combination trials of immunotherapies with ALK inhibitors for NSCLC are also foreseen in the future to overcome or delay resistance mechanisms to monotherapy. ${ }^{70-72}$ 


\section{Additional ALK inhibitors currently in clinical development}

Various next-generation ATP-competitive ALK inhibitors are in clinical development. AP26113 is a dual ALK/EGFR inhibitor that has activity against EGFR T790M in cell and mouse models of NSCLC. ${ }^{73}$ ASP3026 demonstrates activity against ALK mutants F1174L, R1275Q, and L1196M. Acquired resistance cell line models to ASP3026 demonstrated the presence of various secondary point mutations (G1128S, C1156F, I1171N/T, F1174I, N1178H, $\mathrm{E} 1210 \mathrm{~K}$, and $\mathrm{C} 1156 \mathrm{~F} / \mathrm{D} 1203 \mathrm{~N}$ ), which were variably sensitive to ceritinib, alectinib, and AP26113 depending on the specific mutation. PF-06463922, a highly potent-selective inhibitor of both ALK and ROS1, demonstrated activity against all mutation types. ${ }^{74}$ Indeed, it has the distinctive profile of activity against G1202R, in addition to L1196M and G11269A, in low nanomolar concentrations. RXDX-101 also inhibits tropomyosin-related kinase-A (TRK-A), TRK-B, and TRK-C in addition to ALK and ROS1. It has activity against the crizotinib-resistant ALK mutants L1196M and C1156Y. ${ }^{75-77}$ Another agent X-396 also has activity against these two mutations. ${ }^{78}$ Tables 1 and 2 list a summary of their clinical profile to date.

Inhibition of Hsp90 represents an interesting approach for treating ALK-positive NSCLC. Hsp90 is a molecular chaperone that assists in proper protein folding, stabilization, and function. It has been observed that many of the proteins to which it binds are involved in signaling pathways required for oncogenesis, leading to the development and study of Hsp90 inhibitors in cancer treatment. ${ }^{79} \mathrm{Hsp} 90$ inhibitors have been effective against ALK-positive NSCLC.

In preclinical data, Hsp90 inhibitors were effective against both cell lines and xenograft models harboring the EML4ALK mutation. ${ }^{80}$ Recent clinical data have demonstrated antitumor activity of Hsp90 inhibitor in ALK-positive NSCLC ${ }^{81-83}$ confirming the preclinical observations.

Sequist et a ${ }^{81}$ conducted a Phase II trial studying IPI-504, a potent inhibitor of Hsp-90, in patients with advanced NSCLC who had progressed on EGFR inhibitor therapy. The study recruited 76 patients where five demonstrated a PR to IPI-504, out of which three patients were identified with ALK mutations. ${ }^{81}$

Post hoc analysis of a Phase II study with ganetespib showed significant efficacy in ALK-translocated NSCLC. The trial enrolled 99 patients with NSCLC into three cohorts based on mutation status: EGFR-mutant, KRAS-mutant, or WT for both EGFR and KRAS. Eight of 23 patients in the WT cohort subsequently had EML4-ALK mutations identified. Of

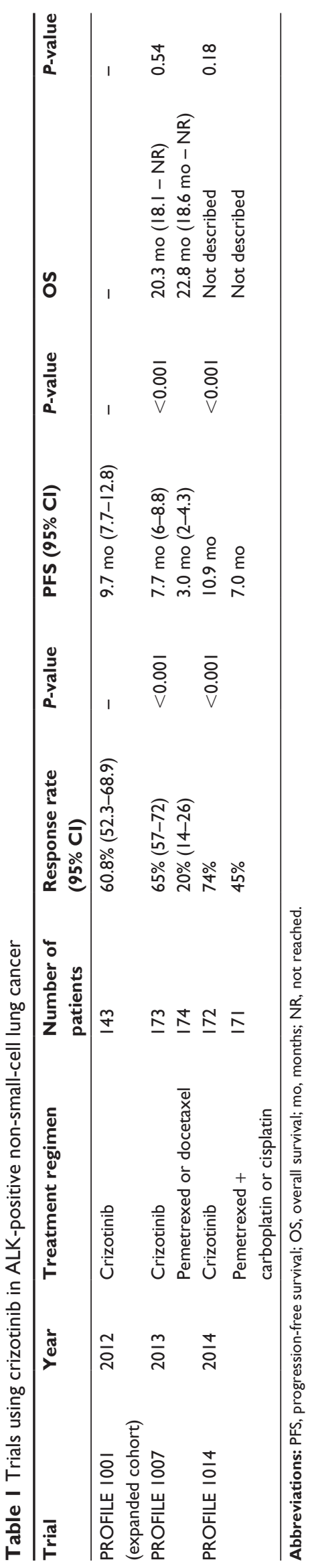


Table 2 Selected ALK inhibitors currently in the clinic or under clinical development

\begin{tabular}{|c|c|c|c|c|c|c|}
\hline \multirow[t]{2}{*}{ Drugs } & \multirow{2}{*}{$\begin{array}{l}\text { Current } \\
\text { phase }\end{array}$} & \multirow[t]{2}{*}{ Toxicity } & \multicolumn{2}{|l|}{ Response } & \multicolumn{2}{|l|}{ CNS response } \\
\hline & & & Crizotinib-naïve & $\begin{array}{l}\text { Crizotinib- } \\
\text { resistant }\end{array}$ & Crizotinib-naïve & $\begin{array}{l}\text { Crizotinib- } \\
\text { resistant }\end{array}$ \\
\hline $\begin{array}{l}\text { Crizotinib } \\
(\mathrm{PF}-0234 \mathrm{I066})\end{array}$ & III & $\begin{array}{l}\text { Visual disturbances, } \\
\text { nausea, vomiting, } \\
\text { constipation, edema }\end{array}$ & - & - & \multicolumn{2}{|c|}{$\begin{array}{l}\text { Untreated: Intracranial DCR - 56\% } \\
\text { (95\% Cl, 46-66) } \\
\text { Intracranial TTP: 6.7-16.4 mo85 } \\
\text { Treated with radiotherapy: } \\
\text { Intracranial DCR - 62\% (95\% } \\
\text { Cl, 54-70) } \\
\text { mTTP: I3.2 mo }(95 \% \mathrm{Cl}, 9.9-\mathrm{NR})^{85}\end{array}$} \\
\hline $\begin{array}{l}\text { Ceritinib } \\
(\text { LDK378) }\end{array}$ & $\| / / I I$ & $\begin{array}{l}\text { Diarrhea, } \\
\text { elevated transaminases }\end{array}$ & $\begin{array}{l}\text { ORR - 4l/59 } \\
(66 \%)^{41} \\
\text { mPFS: not reached }{ }^{41}\end{array}$ & $\begin{array}{l}\text { ORR }-67 / 121(54.6 \%)^{41} \\
\text { mPFS: } 6.9 \mathrm{mo}^{41}\end{array}$ & $\begin{array}{l}\text { ORR } 75 \%(95 \% \\
\mathrm{Cl}, 19.4-99.4)^{41}\end{array}$ & $\begin{array}{l}\text { ORR } 40 \%(95 \% \\
\mathrm{Cl}, 12.2-73.8)^{41}\end{array}$ \\
\hline $\begin{array}{l}\text { Alectinib } \\
\text { (CH542802/ } \\
\text { RO542802) }\end{array}$ & $\| / I I I$ & $\begin{array}{l}\text { Nausea, fatigue, myalgias, } \\
\text { neutropenia, elevated CPK }\end{array}$ & $\begin{array}{l}\text { Phase I/II: ORR - } \\
43 / 46(93.5 \%)^{46}\end{array}$ & $\begin{array}{l}\text { Phase I/II: ORR - 24/44 (55\%), } \\
S D-16 / 44(36 \%)^{47}\end{array}$ & & $\begin{array}{l}\text { Phase I/II: } \\
\text { ORR - I I/2I } \\
(52 \%)^{47}\end{array}$ \\
\hline AP26113 & $\mathrm{I} / \mathrm{II}$ & Nausea, fatigue, diarrhea & - & ORR - 24/38 $(63 \%)^{86}$ & - & $\begin{array}{l}O R R-6 / 10 \\
S D-2 / 10 \\
P D-2 / 10^{86}\end{array}$ \\
\hline ASP-3026 & IB & $\begin{array}{l}\text { Nausea, vomiting, } \\
\text { constipation, } \\
\text { abdominal pain }\end{array}$ & - & $\begin{array}{l}\text { PR: } 7 / I 5(49 \%) \\
\text { SD: } 8 / I 5(50 \%)^{87} \\
\text { mPFS: } 5.9 \text { mo }(95 \% \mathrm{Cl} \\
3.8-9.4)^{87}\end{array}$ & - & - \\
\hline$X-396$ & $\mathrm{I} / \mathrm{II}$ & $\mathrm{N} / \mathrm{A}$ & $\begin{array}{l}\text { I3 ALK+: } 3 \text { crizotinit } \\
\text { resistant - among } 6 \\
\text { PR } 83 \% \text { (unsure of } \mathrm{cr}\end{array}$ & $\begin{array}{l}\text {-naive and } 10 \text { crizotinib- } \\
\text { LK + patients: SD I7\% and } \\
\text { zotinib-naive or -resistant })^{78}\end{array}$ & & \\
\hline
\end{tabular}

Abbreviations: TTP, time to progression; $\mathrm{Cl}$, confidence interval; ORR, overall response rate; SD, standard deviation; PFS, progression-free survival; mPFS, median progression-free survival; ALK, anaplastic lymphoma kinase; CNS, central nervous system; CPK, creatine phosphokinase; wk, weeks; mo, months; DCR, disease control rate; $\mathrm{NR}$, not reached; mTTP, median time to progression; N/A, not available; PD, progressive disease.

this subset, four patients demonstrated a PR, three had stable disease, and one had progressive disease on treatment. ${ }^{83}$

Hsp90 inhibitors such as ganetespib have been shown to possess preclinical activity in crizotinib-resistant models of ALK-positive NSCLC in whom resistance was sustained by the presence of "ALK-dominant" mechanisms (ie, secondary point mutations in the ALK kinase domain as well as ALK gene amplification). ${ }^{84}$ In addition, HSP90 inhibition holds the potential to be effective regardless of the type of secondary ALK mutation in contrast to the next-generation ALK inhibitors discussed earlier, which have varying efficacy depending on the mutation type. Phase II trials are currently being conducted to evaluate various Hsp90-inhibitor, either as monotherapy or in combination with an ALK inhibitor in either ALK inhibitor-naïve or -resistant population (NCT01712217, NCT01752400).

\section{Conclusion}

Crizotinib, an ALK inhibitor, has now been proven to be the preferred first-line therapy for ALK-positive NSCLC over platinum-based chemotherapy. FISH is currently considered as the gold standard testing modality for detecting ALK+ NSCLC. Emerging data suggest that NGS may potentially complement or even supplant the diagnostic technique for detecting ALK-positive cancers. Hsp90 inhibitors are also under study to treat ALK-positive NSCLC. A growing concern for disease relapse in the CNS as well as acquired resistance to crizotinib has led to the discovery of second- and third-generation ALK inhibitors. Clinical trials utilizing combination strategies with other signaling inhibitors are being evaluated to delay or overcome resistance to monotherapy. With the anticipated approval of immunotherapy agents as a treatment option for patients with nonsquamous NSCLC, it is foreseen that combination trials of these drugs with ALK inhibitors will be conducted in the near future.

\section{Disclosure}

The authors report no conflicts of interest in this work.

\section{References}

1. Cancer.gov. [Homepage on the Internet]. Atlanta, GA: American Cancer Society. Available from: http://www.cancer.gov/. Accessed April 1, 2015.

2. Siegel RL, Miller KD, Jemal A. Cancer statistics, 2015. CA Cancer J Clin. 2015;65(1):5-29.

3. Scagliotti GV, De Marinis F, Rinaldi M, et al. Phase III randomized trial comparing three platinum-based doublets in advanced non-small-cell lung cancer. J Clin Oncol. 2002;20(21):4285-4291. 
4. Metro G, Crinò L. Novel molecular trends in the management of advanced nonsmall-cell lung cancer. Expert Rev Anticancer Ther. 2012;12(6):729-732.

5. Reungwetwattana T, Dy GK. Targeted therapies in development for non-small cell lung cancer. J Carcinog. 2013;12:22.

6. Shaw AT, Solomon B. Targeting anaplastic lymphoma kinase in lung cancer. Clin Cancer Res. 2011;17(8):2081-2086.

7. Martelli MP, Sozzi G, Hernandez L, et al. EML4-ALK rearrangement in non-small cell lung cancer and non-tumor lung tissues. Am J Pathol. 2009;174(2):661-670.

8. Lee JA, Bubendorf L, Stahel R, Peters S. Testing for anaplastic lymphoma kinase rearrangement to target crizotinib therapy: oncology, pathology and health economic perspectives. Expert Rev Anticancer Ther. 2013;13(5):625-636.

9. Yi ES, Chung JH, Kulig K, Kerr KM. Detection of anaplastic lymphoma kinase (ALK) gene rearrangement in non-small cell lung cancer and related issues in ALK inhibitor therapy: a literature review. Mol Diagn Ther. 2012;16(3):143-150.

10. Weickhardt AJ, Aisner DL, Franklin WA, Varella-Garcia M, Doebele RC, Camidge DR. Diagnostic assays for identification of anaplastic lymphoma kinase-positive non-small cell lung cancer. Cancer. 2013;119(8):1467-1477.

11. Soda M, Isobe $K$, Inoue A, et al. A prospective PCR-based screening for the EML4-ALK oncogene in non-small cell lung cancer. Clin Cancer Res. 2012;18(20):5682-5689.

12. Wu YC, Chang IC, Wang CL, et al. Comparison of IHC, FISH and RTPCR methods for detection of $A L K$ rearrangements in 312 non-small cell lung cancer patients in Taiwan. PLoS One. 2013;8(8):e70839.

13. Wallander ML, Geiersbach KB, Tripp SR, Layfield LJ. Comparison of reverse transcription-polymerase chain reaction, immunohistochemistry, and fluorescence in situ hybridization methodologies for detection of echinoderm microtubule-associated proteinlike 4-anaplastic lymphoma kinase fusion-positive non-small cell lung carcinoma: implications for optimal clinical testing. Arch Pathol Lab Med. 2012;136(7): 796-803.

14. Teixido C, Karachaliou N, Peg V, Gimenez-Capitan A, Rosell R. Concordance of IHC, FISH and RT-PCR for EML4-ALK rearrangements. Transl Lung Cancer Res. 2014;3(2):70-74.

15. Mino-Kenudson M, Chirieac LR, Law K, et al. A novel, highly sensitive antibody allows for the routine detection of ALK-rearranged lung adenocarcinomas by standard immunohistochemistry. Clin Cancer Res. 2010;16(5):1561-1571.

16. Kelleher FC, McDermott R. The emerging pathogenic and therapeutic importance of the anaplastic lymphoma kinase gene. Eur J Cancer. 2010;46(13):2357-2368.

17. Peled N, Palmer G, Hirsch FR, et al. Next-generation sequencing identifies and immunohistochemistry confirms a novel crizotinib-sensitive ALK rearrangement in a patient with metastatic non-small-cell lung cancer. J Thorac Oncol. 2012;7(9):e14-e16.

18. Ali SM, Ou S-HI, He J. Identifying ALK rearrangements that are not detected by FISH with targeted next-generation sequencing of lung carcinoma. Poster presented at: Proceedings of the 50th Annual Meeting of American Society of Clinical Oncology; May 30-June 3, 2014; Chicago, IL.

19. Catalogue of somatic mutations in cancer. Cambridge, UK: Wellcome Trust Sanger Institute. Available from: http://cancer.sanger.ac.uk/cosmic/fusion. Accessed May 4, 2015.

20. Shaw AT, Yeap BY, Mino-Kenudson M, et al. Clinical features and outcome of patients with non-small-cell lung cancer who harbor EML4ALK. J Clin Oncol. 2009;27(26):4247-4253.

21. Camidge DR, Doebele RC. Treating ALK-positive lung cancer-early successes and future challenges. Nat Rev Clin Oncol. 2012;9(5): 268-277.

22. Blackhall FH, Peters S, Bubendorf L, et al. Prevalence and clinical outcomes for patients with ALK-positive resected stage I-III adenocarcinoma: results from the European Thoracic Oncology Platform Lungscape Project. J Clin Oncol. 2014;32(25):2780-2787.
23. http://www.wcrf.org/int/cancer-facts-figures/worldwide-data [Homepage on the Internet]. Cancer Incidence and Mortality Worldwide: IARC CancerBase Number 11 [Internet]. Lyon, France: International Agency for Research on Cancer; 2014. Available from: http://globocan.iarc.fr/. Accessed January 16, 2015.

24. Takahashi T, Sonobe M, Kobayashi M, et al. Clinicopathologic features of non-small-cell lung cancer with EML4-ALK fusion gene. Ann Surg Oncol. 2010;17(3):889-897.

25. Yamamoto S, Korn RL, Oklu R, et al. ALK molecular phenotype in nonsmall cell lung cancer: CT radiogenomic characterization. Radiology. 2014;272(2):568-576.

26. Camidge DR, Kono SA, Lu X, et al. Anaplastic lymphoma kinase gene rearrangements in non-small cell lung cancer are associated with prolonged progression-free survival on pemetrexed. J Thorac Oncol. 2011;6(4):774-780.

27. Lee JO, Kim TM, Lee SH, et al. Anaplastic lymphoma kinase translocation: a predictive biomarker of pemetrexed in patients with non-small cell lung cancer. J Thorac Oncol. 2011;6(9):1474-1480.

28. Shaw AT, Varghese AM, Solomon BJ, et al. Pemetrexed-based chemotherapy in patients with advanced, ALK-positive non-small cell lung cancer. Ann Oncol. 2013;24(1):59-66.

29. Soda M, Takada S, Takeuchi K, et al. A mouse model for EML4ALK-positive lung cancer. Proc Natl Acad Sci U S A. 2008;105(50): 19893-19897

30. Cui J, Kania RS, Edwards MP. Crizotinib. In: Lackey K, Roth B, editors. Medicinal Chemistry Approaches to Personalized Medicine. Vol 59, Chapter 3, Section 3.3. New York, NY: Wiley. 2014.

31. Kwak EL, Bang YJ, Camidge DR, et al. Anaplastic lymphoma kinase inhibition in non-small-cell lung cancer. N Engl J Med. 2010;363(18): 1693-1703.

32. Camidge DR, Bang YJ, Kwak EL, et al. Activity and safety of crizotinib in patients with ALK-positive non-small-cell lung cancer: updated results from a phase 1 study. Lancet Oncol. 2012;13(10):1011-1019.

33. Crinò L, Kim D, Riely GJ, et al. Initial phase II results with crizotinib in advanced ALK-positive non-small cell lung cancer (NSCLC): PROFILE 1005. Poster presented at: Proceedings of the 47th Annual Meeting of American Society of Clinical Oncology; June 3-7, 2011; Chicago, IL.

34. Kim D, Ahn M, Shi Y, et al. Updated results of a global Phase II study with crizotinib in advanced ALK positive non-small cell lung cancer (NSCLC) [abstract]. Ann Oncol. 2012;23(Suppl 9):402.

35. Friboulet L, Li N, Katayama R, et al. The ALK inhibitor ceritinib overcomes crizotinib resistance in non-small cell lung cancer. Cancer Discov. 2014;4(6):662-673.

36. National Cancer Institute. Erlotinib hydrochloride or crizotinib and chemoradiation therapy in treating patients with stage iii non-small cell lung cancer (NSCLC). Available from: https://clinicaltrials.gov/ct2/ show/results/NCT01822496. NLM Identifier: NCT01822496. Accessed July 24, 2015.

37. Shaw AT, Kim DW, Nakagawa K, et al. Crizotinib versus chemotherapy in advanced ALK-positive lung cancer. $N$ Engl J Med. 2013;368(25): 2385-2394.

38. Solomon BJ, Mok T, Kim DW, et al. First-line crizotinib versus hemotherapy in ALK-positive lung cancer. NEngl J Med. 2014;371(23): 2167-2177.

39. Lovly CM, Heuckmann JM, de Stanchina E, et al. Insights into ALKdriven cancers revealed through development of novel ALK tyrosine kinase inhibitors. Cancer Res. 2011;71(14):4920-4931.

40. Shaw AT, Kim DW, Mehra R, et al. Ceritinib in ALK-rearranged nonsmall-cell lung cancer. N Engl J Med. 2014;370(13):1189-1197.

41. Kim DW, Mehra R, Tan SW, et al. Ceritinib in advanced anaplastic lymphoma kinase (ALK)-rearranged (ALK+) non-small cell lung cancer (NSCLC): results of the ASCEND-1 trial. Poster presented at: Proceedings of the 50th Annual Meeting of American Society of Clinical Oncology; May 30-June 3, 2014, Chicago; IL.

42. Gainor JF, Tan DS, De Pao T, et al. Progression-free and overall survival in ALK-positive NSCLC patients treated with sequential crizotinib and certinib. Clin Cancer Res. 2015;21(12):2745-2752. 
43. Novartis Pharmaceuticals. LDK378 versus chemotherapy in previously untreated patients with ALK rearranged non-small cell lung cancer. Available at: https://clinicaltrials.gov/ct2/results?term=NCT0 $1828099 \&$ Search=Search. NLM Identifier: NCT01828099. Accessed September 1, 2014.

44. Sakamoto H, Tsukaguchi T, Hiroshima S, et al. CH5424802, a selective ALK inhibitor capable of blocking the resistant gatekeeper mutant. Cancer Cell. 2011;19(5):679-690.

45. Kodama T, Tsukaguchi T, Yoshida M, Kondoh O, Sakamoto H. Selective ALK inhibitor alectinib with potent antitumor activity in models of crizotinib resistance. Cancer Lett. 2014;351(2):215-221.

46. Seto T, Kiura K, Nishio M, et al. CH5424802 (RO5424802) for patients with ALK-rearranged advanced non-small-cell lung cancer (AF-001JP study): a single-arm, open-label, phase 1-2 study. Lancet Oncol. 2013;14(7):590-598.

47. Gadgeel SM, Gandhi L, Riely GJ, et al. Safety and activity of alectinib against systemic disease and brain metastases in patients with crizotinibresistant ALK-rearranged non-small-cell lung cancer (AF-002JG) results from the dose-finding portion of a phase 1/2 study. Lancet Oncol 2014;15(10):1119-1128.

48. Nakagawa K, Hida T, Seto T, editors, et al. Antitumor activity of alectinib (CH5424802/ RO5424802) for ALK-rearranged NSCLC with or without prior crizotinib treatment in bioequivalence study. Poster presented at: Proceedings of the 50th Annual Meeting of American Society of Clinical Oncology; May 30-June 3, 2014; Chicago, IL.

49. Doebele RC, Lu X, Sumey C, et al. Oncogene status predicts patterns of metastatic spread in treatment-naive nonsmall cell lung cancer. Cancer. 2012;118(18):4502-4511.

50. Kang HJ, Lim HJ, Park JS, et al. Comparison of clinical characteristics between patients with ALK-positive and EGFR-positive lung adenocarcinoma. Respir Med. 2014;108(2):388-394.

51. Gofton TE, Graber J, Carver A. Identifying the palliative care needs of patients living with cerebral tumors and metastases: a retrospective analysis. J Neurooncol. 2012;108(3):527-534.

52. Bauml J, Mick R, Zhang Y, et al. Determinants of survival in advanced non-small-cell lung cancer in the era of targeted therapies. Clin Lung Cancer. 2013;14(5):581-591.

53. Barlesi F, Gervais R, Lena H, et al. Pemetrexed and cisplatin as first-line chemotherapy for advanced non-small-cell lung cancer (NSCLC) with asymptomatic inoperable brain metastases: a multicenter phase II trial (GFPC 07-01). Ann Oncol. 2011;22(11):2466-2470.

54. Kumthekar P, Grimm SA, Avram AJ, et al. Pharmacokinetics and efficacy of pemetrexed in patients with brain or leptomeningeal metastases. $J$ Neurooncol. 2013;112(2):247-255.

55. Kaneda H, Okamoto I, Nakagawa K. Rapid response of brain metastasis to crizotinib in a patients with ALK rearrangement - positive non-smallcell lung cancer. J Thorac Oncol. 2013;8(4):e32-e33.

56. Costa DB, Kobayashi S, Pandya SS, et al. CSF concentration of the anaplastic lymphoma kinase inhibitor crizotinib. J Clin Oncol. 2011;29(15):e443-e445.

57. Gainor JF, Ou SH, Logan J, Borges LF, Shaw AT. The central nervous system as a sanctuary site in ALK-positive non-small cell lung cancer. J Thorac Oncol. 2013;8(12):1570-1573.

58. Weickhardt AJ, Scheier B, Burke JM, et al. Local ablative therapy of oligoprogressive disease prolongs disease control by tyrosine kinase inhibitors in oncogene-addicted non-small-cell lung cancer. J Thorac Oncol. 2012;7(12):1807-1814.

59. Steuer CE, Ramalingam SS. ALK-positive non-small cell lung cancer: mechanisms of resistance and emerging treatment options. Cancer. 2014;120(16):2392-2402.

60. Gainor JF, Friboulet J, Katayama R, et al. Evolution of resistance in ALK-positive patients treated with ALK tyrosine kinase inhibitors (TKIs). Poster presented at: Proceedings of the 50th Annual Meeting of American Society of Clinical Oncology; May 30-June 3, 2014; Chicago, IL.

61. Katayama R, Friboulet L, Koike S, et al. Two novel ALK mutations mediate acquired resistance to the next-generation ALK inhibitor alectinib. Clin Cancer Res. 2014;20(22):5686-5696.
62. Ou SH, Greebowe J, Khan ZU, et al. I 1171 missense mutation (particularly $\mathrm{I} 1171 \mathrm{~N}$ ) is a common resistance mutation in ALK-positive NSCLC patients who have progressive disease while on alectinib and is sensitive to certinib. Lung Cancer. 2015;88(2):231-234.

63. Katayama R, Khan TM, Benes C, et al. Therapeutic strategies to overcome crizotinib resistance in non-small cell lung cancers harboring the fusion oncogene EML4-ALK. Proc Natl Acad Sci U S A. 2011; 108(18):7535-7540.

64. Katayama R, Shaw AT, Khan TM, et al. Mechanisms of acquired crizotinib resistance in ALK-rearranged lung cancers. Sci Transl Med. 2012;4(120):120ra17.

65. Doebele RC, Pilling AB, Aisner DL, et al. Mechanisms of resistance to crizotinib in patients with ALK gene rearranged non-small cell lung cancer. Clin Cancer Res. 2012;18(5):1472-1482.

66. Sasaki T, Koivunen J, Ogino A, et al. A novel ALK secondary mutation and EGFR signaling cause resistance to ALK kinase inhibitors. Cancer Res. 2011;71(18):6051-6060.

67. Kogita A, Togashi Y, Hayashi H, et al. Activated MET acts as a salvage signal after treatment with alectinib, a selective ALK inhibitor, in ALK-positive non-small cell lung cancer. Int J Oncol. 2015;46(3): 1025-1030.

68. Gouji T, Takashi S, Mitsuhiro J, Yukito I. Crizotinib can overcome acquired resistance to $\mathrm{CH} 5424802$ : is amplification of the MET gene a key factor? J Thorac Oncol. 2014;9(3):e27-e28.

69. Crystal AS, Shaw AT, Sequist LV, et al. Patient-derived models of acquired resistance can identify effective drug combinations for cancer. Science. 2014;346(6216):1480-1486.

70. Ota K, Azuma K, Kawahara A, et al. Induction of PD-L1 expression by the EML4-ALK oncoprotein and downstream signaling pathways in non-small cell lung cancer. Clin Cancer Res. Epub 2015 May 27.

71. news.bms.com. [Homepage on the Internet]. Bristol-Myers squibb announces collaboration to evaluate opdivo (nivolumab) in combination with targeted therapies from novartis to treat non-small cell lung cancer (NSCLC). Available from: http://news.bms.com/press-release/ rd-news/bristol-myers-squibb-announces-collaboration-evaluateopdivo-nivolumab-combina. Accessed July 24, 2015.

72. Gainor JF, Sequist LV, Shaw AT, et al. Clinical correlation and frequency of programmed death ligand-1 (PD-L1) expression in EGFR-mutant and ALK-rearranged non-small cell lung cancer (NSCLC). Poster presented at: Proceedings of the 51st Annual Meeting of American Society of Clinical Oncology; May 29-June 2, 2015; Chicago, IL.

73. Rivera VM, Wang F, Anjum R, et al. AP26113 is a dual ALK/EGFR inhibitor: characterization against EGFR T790M in cell and mouse models of NSCLC. Cell. 2012;1:100.

74. Mologni L, Ceccon M, Pirola A, et al. NPM/ ALK mutants resistant to ASP 3026 display variable sensitivity to alternative ALK inhibitors but succumb to the novel compound PF-06463922. Oncotarget. 2015;6(8):5720-5734.

75. Ardini E, Menichincheri M, De Ponti C, et al. Characterization of NMSE628, a small molecule inhibitor of anaplastic lymphoma kinase with antitumor efficacy in ALK-dependent lymphoma and non-small cell lung cancer models [EORTC-NCIAACR abstract A243]. Mol Cancer Ther. 2009;8(12 Suppl):A244.

76. Ardini $\mathrm{E}$, Menichincheri $\mathrm{M}, \mathrm{Banfi} \mathrm{P}$, et al. In vitro and in vivo activity of NMS-E628 against ALK mutations resistant to Xalkori [EORTC-NCIAACR abstract A232]. Mol Cancer Ther. 2011;10(11 Suppl):A232.

77. De Braud FG, Pilla L, Niger M, et al. Phase 1 open label, dose escalation study of RXDX101, an oral pan-trk, ROS1, and ALK inhibitor, in patients with advanced solid tumors with relevant molecular alterations. Poster presented at: Proceedings of the 50th Annual Meeting of American Society of Clinical Oncology; May 30-June 3, 2014; Chicago, IL.

78. Horn L, Infante JR, Blumenschein GR, et al. A phase I trial of X-396, a novel ALK inhibitor, in patients with advanced solid tumors. Poster presented at: Proceedings of the 50th Annual Meeting of American Society of Clinical Oncology; May 30-June 3, 2014; Chicago, IL. 
79. Neckers L. Hsp90 inhibitors as novel cancer chemotherapeutic agents. Trends Mol Med. 2002;8:S55-S61.

80. Chen Z, Sasaki T, Tan X, et al. Inhibition of ALK, PI3K/MEK, and HSP90 in murine lung adenocarcinoma induced by EML4-ALK fusion oncogene. Cancer Res. 2010;70(23):9827-9836.

81. Sequist LV, Gettinger S, Senzer NN, et al. Activity of IPI-504, a novel heat-shock protein 90 inhibitor, in patients with molecularly defined non-small-cell lung cancer. J Clin Oncol. 2010;28(33):4953-4960.

82. Felip E, Carcereny E, Barlesi F, et al. Phase II activity of the Hsp 90 inhibitor AUY922 in patients with ALK-rearranged (ALK+) or EGFRmutated advanced non-small cell lung cancer [abstract]. Ann Oncol. 2012;23 (Suppl 9):438.

83. Socinski MA, Goldman J, El-Hariry I, et al. A multicenter phase II study of ganetespib monotherapy in patients with genotypically defined advanced non-small cell lung cancer. Clin Cancer Res. 2013;19(11):3068-3077.

84. Sang J, Acquaviva J, Friedland JC, et al. Targeted inhibition of the molecular chaperone Hsp90 overcomes ALK inhibitor resistance in non-small cell lung cancer. Cancer Discov. 2013;3(4):430-443.
85. Costa DB, Shaw AT, Ou SH, Solomon BJ, Riley GJ, Ahn MJ. Clinical experience with crizotinib in patients with advanced ALK-rearranged non-small-cell lung cancer and brain metastases. J Clin Oncol. 2015;33(17):1881-1888.

86. Gettinger S, Bazhenova L, Salgia R, et al. ALK Inhibitor AP26113 in patients with advanced malignancies, including ALKp non-small cell lung cancer (NSCLC): updated efficacy and safety data. Poster presented at: Proceedings of the ESMO 2014 Congress; September 26-30, 2014; Madrid, Spain. Lugano, Switzerland: European Society for Medical Oncology; 2014. Abstract no 1292P.

87. Maitland ML, Ou S-HI, Tolcher AW, et al. Safety, activity, and pharmacokinetics of an oral anaplastic lymphoma kinase (ALK) inhibitor, ASP3026, observed in a "fast follower" phase 1 trial design. Poster presented at: Proceedings of the 50th Annual Meeting of American Society of Clinical Oncology; May 30-June 3, 2014; Chicago, IL.

\section{Publish your work in this journal}

Lung Cancer: Targets and Therapy is an international, peer-reviewed, open access journal focusing on lung cancer research, identification of therapeutic targets and the optimal use of preventative and integrated treatment interventions to achieve improved outcomes, enhanced survival and quality of life for the cancer patient. Specific topics covered in the journal include: Epidemiology, detection and screening; Cellular research and biomarkers; Identification of biotargets and agents with novel

Submit your manuscript here: http://www.dovepress.com/lung-cancer-targets--therapy-journa

\section{Dovepress}

mechanisms of action; Optimal clinical use of existing anticancer agents, including combination therapies; Radiation and surgery; Palliative care; Patient adherence, quality of life, satisfaction; Health economic evaluations. The manuscript management system is completely online and includes a very quick and fair peer-review system. Visit http://www.dovepress.com/testimonials.php to read real quotes from published authors. 